\title{
Validation of a portable system for spatial-temporal gait parameters based on a single inertial measurement unit and a mobile application
}

\author{
Pablo Aqueveque (1), Britam Gómez (1), Francisco Saavedra (1), Cristian Canales (2), \\ Simón Contreras (2), Paulina Ortega-Bastidas (3), Roberto Cano-de-la-Cuerda (4) \\ (1) Electrical Engineering Department, Faculty of Enginering, Universidad de Concepción, \\ Concepcion, Biobio, Chile; (2) Mechanical Engineering Department, Faculty of Engineering, \\ Universidad de Concepción, Concepcion, Biobio, Chile; (3) Kinesiology Department, Faculty \\ of Medicine, Universidad de Concepción, Concepción, Biobio, Chile; (4) Physiotherapy, \\ Occupational Therapy, Universidad Rey Juan Carlos, Alcorcón, Madrid, Spain.
}

This article is distributed under the terms of the Creative Commons Attribution Noncommercial License (CC BY-NC 4.0) which permits any noncommercial use, distribution, and reproduction in any medium, provided the original author( $s$ ) and source are credited.

\begin{abstract}
There is a lack of commercially available low-cost technologies to assess gait clinically in noncontrolled environments. As a consequence of this, there has been poor massification of motion measurement technologies that are both objective and reliable in nature. Advances about the study of gait and its interpretation in recent years using inertial sensors have allowed proposing acceptable alternatives for the development of portable and low-cost systems that contribute to people's health in places and institutions that cannot acquire or maintain the operation of commercially available systems. A system based on a custom single Inertial Measurement Unit and a mobile application is proposed. Thus, an investigation is carried out using methodologies and algorithms found in the literature in order to get the main gait events and the spatial-temporal gait parameters. Twenty healthy Chilean subjects were assessed using a motion capture system simultaneously with the proposed tool. The results show that it is possible to estimate temporal gait parameters with slight differences respect gold--standard. We reach maximum mean differences of $-2.35 \pm 5.02$ [step $/ \mathrm{min}$ ] for cadence, $0.03 \pm 0.04$ [sec] for stride time, $0.02 \pm 0.03$ [sec] for step time, \pm 0.02 [sec] for a single support time, $0.01 \pm 0.02$ [sec] for double support time and $0.01 \pm 0.03[\mathrm{~m}]$ for step length. As a result of experimental findings, we propose a new technological tool that can perform gait analysis. Our proposed system is user-friendly, low-cost, and portable. Therefore, we suggest that it could be an attractive technological tool that healthcare professionals could harness to objectively measure gait in environments that are either within the community or controlled. We also suggest that the tool could be used in countries where advanced clinical tools cannot be acquired. Therefore, we propose in this paper that our system is an attractive, alternative system that can be used for gait analysis by health professionals worldwide.
\end{abstract}

Key Words: Gait analysis, Spatial-temporal gait parameters, Inertial sensors

Eur J Transl Myol 30 (2): 268-276, 2020

There is a lack of commercially available low-cost and holistically validated technologies to capture human motion with precision and reliability. This has contributed to the poor massification of objective measurement alternatives to assess gait, mainly in undeveloped or developing countries, where not all have the capability to incorporate technology into their measurement and evaluation methodologies. ${ }^{1,-3}$ Many clinical tests observe gait quality, like the 6-meters, 10meters and 25-meters gait tests. Rehabilitation professionals can implement them in non-controlled environments, e.g., outside hospitals or rehabilitation institutes. However, the limitation of these methods is their dependency on the observation and expertise of the evaluator, obtaining a single global parameter to characterize it. ${ }^{4,5}$ In the last decades, scientists and developers have proposed, and design inertial sensorsbased alternatives for the analysis and monitoring of human movement, due to the reduction in size, price and energy consumption for these sensors. ${ }^{6,7}$ These alternatives vary not only in the number of sensors and communication techniques, but also in the number of parameters that can be measured to evaluate gait. ${ }^{8-14} \mathrm{On}$ 
the other side, technological advances in mobile devices from a portability point of view and processing power have allowed the implementation of attractive and functional solutions for the ambulatory analysis of human movement outside a laboratory ${ }^{15}$ However, most of these commercially available systems remain at a high cost, or they are poorly validated,${ }^{16}$ which limits their use in, for example, rural areas of difficult access. Although several works present comparative studies on the performance of different methodologies based on inertial sensors or Inertial Measurement Units (IMU) for the estimation of spatial-temporal gait parameters, the most are designed in highly controlled environments that avoid reproducing the results in daily life conditions or outside a laboratory. Furthermore, these works are focused only on characteristics related to precision or error estimation, leaving aside characteristics such as ease of implementation, comfort and price, which would allow the use of inertial sensors for the clinical analysis of human movement. ${ }^{12,17-30}$

For all these reasons, we present a deep review of wearable sensor - algorithms systems based on inertial sensors for spatial-temporal gait analysis. In addition, we designed and validated a portable and easy-to-use system based on this technology, in order to facilitate and promote this objective technological tool. The tool may be used for gait evaluation in conditions and environments where the acquisition of commercially available gait assessment technology is not possible.

\section{State of the art}

Spatial-temporal gait parameters are indexes that describe in an objective and precise way the state of gait. In optoelectronic systems for motion analysis, the events of foot-off or final contact (FC) and heel strike or initial contact (IC) are used to obtain these parameters. Numerous methodologies and inertial sensor-based algorithms have been developed for the identification of the events of FC and IC from different data -- lineal or vectorial accelerations from accelerometers, angular velocities from gyroscopes, angles of the gait cycle -- that vary in the amount and position of the sensors used. ${ }^{8,12,13,18}$ In Table 1a different methods are shown that use inertial sensors to identify and isolate the heel strike or IC and the foot-off FC during the gait cycle, highlighting the its location on the body and if they have been evaluated in healthy subjects or with motor impairments. To develop a simple and easy-to-use alternative, we limit the number of sensors up to 2 units. From the spatial-temporal parameters mentioned, the most complex to estimate accurately using inertial sensors is the step length, because its estimation depends on a double integration process of the accelerations or a single integration of the angular velocities obtained from the inertial sensors, whose calculation yields an accumulative error mainly in low velocities walks. ${ }^{20,21}$ For this, different methods have been proposed that deals with this problem (see Table 1b). Thus, Tables $1 \mathrm{a}$ and $1 \mathrm{~b}$ present different methodologies that are used separately or together, ${ }^{31}$ to describe the spatial and temporal parameters of gait using inertial sensors as an alternative to optoelectronic systems. The mentioned algorithms have been tested under different conditions but always in highly controlled environments, considering not only the environment in which they are performed but also the clothing and footwear of the subjects measured. For this work, it has been decided to implement the methodology presented by González et al. ${ }^{23}$ for the processing of triaxial trunk accelerometry for the estimations of the temporal gait parameters. The choice of this methodology is for the simplicity of the algorithm so it can be implemented in mobile devices for fast data processing, the small number of sensors needed to extract the events from the gait cycle, with a good performance in previous studies, ${ }^{23,30}$ and the location of the sensor in the body that guarantees the comfort of the subjects to be evaluated. Different methodologies have been used to estimate step length, as Rafael et al. ${ }^{20}$ Ziljstra et al. ${ }^{29}$ and Alvarez et al. ${ }^{30}$ They use the same model to implement their algorithms (inverted pendulum model) measuring the trunk displacement with only one sensor. Also, they present good results in their investigations, even in longdistance tests. For the reasons previously mentioned (simplicity, fast data processing, location and quantity of sensors), the algorithm presented by Alvarez et al. ${ }^{30}$ will be used in order to obtain accurate estimation in the implementation using mobile devices for a low-cost, easy-to-use and portable solution. This technological development will be evaluated using an optoelectronic motion measurement system, constituting one of the few alternatives with these characteristics with validation using a Gold-Standard system carried out with Chilean population.

\section{Materials and Methods}

\section{IMU sensor}

The IMU sensor used in this project was developed at the laboratory of Biomedical Engineering of the Universidad de Concepción. It was a custom-designed sensor. The chip sensor used, ${ }^{32}$ has a three-axis accelerometer, a three-axis gyroscope and a three-axis magnetometer, as well as an embedded internal processor able to fusion the magnetic and the inertial data using an extended Kalman filter to deliver the orientation in quaternions to avoid singularities presents in the Euler angles representation. ${ }^{33}$ The orientation angles were obtained with an accuracy of \pm 1 [deg]. All three-axis acceleration data are sampled at $100[\mathrm{~Hz}]$ with a low cost 32-bit microcontroller with an ARM Cortex-M0+ processor and sent to a software application via Bluetooth 3.0. The maximum distance between sender and receiver is 20 meters without risk of occlusion. The entire system is powered by a 500-mAh LiPo battery, which gives 10-hour of autonomy. The IMU sensor with the battery included has dimensions of $40[\mathrm{~mm}] \times 30[\mathrm{~mm}] \times 15[\mathrm{~mm}]$, and a weight of $21[\mathrm{~g}]$ (see Figure 1a). 
Table 1. Methodologies based on inertial sensors for gait analysis.

(a) Methodologies based on inertial sensors for the identification of the initial and final contact events of the gait cycle

\begin{tabular}{|c|c|c|c|c|c|c|}
\hline Method & Sensor & Quantity & Location & Algorithm & Results & Subjects \\
\hline Sedjic et al. & $\begin{array}{l}\text { Tri-axial } \\
\text { accelerometer }\end{array}$ & 1 & L4-L5 & Feature based & $\begin{array}{l}100 \% \text { of the stance events with an average } \\
\text { error of } 1.18 \pm 0.09[\mathrm{~s}] \text { using a motion } \\
\text { capture system. }\end{array}$ & $\begin{array}{l}35 \text { subjects (Healthy, } \\
\text { Parkinson, Peripheral } \\
\text { Neuropathy). }{ }^{22}\end{array}$ \\
\hline $\begin{array}{l}\text { González } \\
\text { et al. }\end{array}$ & $\begin{array}{l}\text { Tri-axial } \\
\text { accelerometer }\end{array}$ & 1 & L3 & Feature based & $\begin{array}{l}100 \% \text { of the events with an average error of } \\
0.013 \pm 0.035[s] \text { for the IC and } 0.009 \pm 0.054 \\
{[s] \text { for the FC using a force platform. }}\end{array}$ & 11 subjects (Healthy). ${ }^{23}$ \\
\hline Kose et al. & $\begin{array}{l}\text { Tri-axial } \\
\text { accelerometer }\end{array}$ & 1 & Waist & $\begin{array}{l}\text { Stationary } \\
\text { Wavelet } \\
\text { Decomposition }\end{array}$ & $\begin{array}{l}96 \% \text { of the events with an error of } \\
0.06 \pm 0.04 \text { [s] for the IC and } 0.05 \pm 0.03 \text { [s] for } \\
\text { the FC using footswitches. }\end{array}$ & 8 subjects (Healthy). ${ }^{24}$ \\
\hline $\begin{array}{l}\text { McCamley } \\
\text { et al. }\end{array}$ & $\begin{array}{l}\text { Tri-axial } \\
\text { accelerometer }\end{array}$ & 1 & Waist & $\begin{array}{l}\text { Wavelet } \\
\text { Decomposition }\end{array}$ & $\begin{array}{l}100 \% \text { of the events with an average error of } \\
0.02 \pm, 0.04[s] \text { for the IC and } 0.03 \pm 0.03[s] \\
\text { for the FC using a } 4 \text {-meter instrumented } \\
\text { mat. }\end{array}$ & 18 subjects (Healthy). ${ }^{25}$ \\
\hline $\begin{array}{l}\text { Aminian et } \\
\text { al. }\end{array}$ & $\begin{array}{l}\text { Tri-axial } \\
\text { accelerometer }\end{array}$ & 2 & $\begin{array}{l}\text { Left and right } \\
\text { thigh }\end{array}$ & Feature based & $\begin{array}{l}100 \% \text { of the stance events with a maximum } \\
\text { error of } 0.74 \pm 0.04 \text { [s] using pressure } \\
\text { sensors under the foot. }\end{array}$ & $\begin{array}{l}12 \text { subjects (Healthy, } \\
\text { Hip Arthroplasty). }{ }^{26}\end{array}$ \\
\hline $\begin{array}{l}\text { Jasiewicz } \\
\text { et al. }\end{array}$ & $\begin{array}{l}\text { Uni-axial } \\
\text { gyroscope }\end{array}$ & 2 & $\begin{array}{l}\text { Left and right } \\
\text { shank }\end{array}$ & Feature based & $\begin{array}{l}100 \% \text { of the events with an average error of } \\
-0.014 \pm 0.023[s] \text { for the IC and }-0.023 \pm 0.028 \\
\text { [s] for the FC using footswitches in healthy } \\
\text { subjects. }\end{array}$ & $\begin{array}{l}41 \text { subjects (Healthy, } \\
\text { Spinal Cord Injury). }{ }^{10}\end{array}$ \\
\hline $\begin{array}{l}\text { Sabatini et } \\
\text { al. }\end{array}$ & $\begin{array}{l}\text { Uni-axial } \\
\text { gyroscope }\end{array}$ & 1 & foot & Feature based & $\begin{array}{l}100 \% \text { of the events with an average error of } \\
-0.002[s] \text { for the IC and } 0.035[s] \text { for the FC } \\
\text { using footswitches }\end{array}$ & 5 subjects (Healthy). ${ }^{27}$ \\
\hline $\begin{array}{l}\text { Aminian et } \\
\text { al. }\end{array}$ & $\begin{array}{l}\text { Uni-axial } \\
\text { gyroscope }\end{array}$ & 2 & $\begin{array}{l}\text { Left and right } \\
\text { shank }\end{array}$ & $\begin{array}{l}\text { Wavelet + Feature } \\
\text { based }\end{array}$ & $\begin{array}{l}100 \% \text { of the } \mathrm{FC} \text { events with an average error } \\
\text { of } 0.01 \text { [s] using pressure sensors under the } \\
\text { foot. }\end{array}$ & 20 Subjects (Healthy). ${ }^{28}$ \\
\hline
\end{tabular}

(b) Methodologies based on inertial sensors for the step length estimation.

\begin{tabular}{|c|c|c|c|c|c|c|c|}
\hline Method & Sensor & Quantity & Location & Model & Algorithm & Results & Subjects \\
\hline $\begin{array}{l}\text { Rafael } \\
\text { et al. }\end{array}$ & $\begin{array}{l}\text { Uni-axial } \\
\text { accelerometer }\end{array}$ & 1 & $\begin{array}{l}\text { Waist, L3- } \\
\text { L4 }\end{array}$ & $\begin{array}{l}\text { Inverted } \\
\text { pendulum } \\
\text { model }\end{array}$ & $\begin{array}{l}\text { Two phase estimation } \\
\text { algorithms: Double integration } \\
\text { of the accelerometer data } \\
\text { during single support phase } \\
\text { with the inverted pendulum } \\
\text { model, and a forward } \\
\text { displacement estimation with } \\
\text { the foot size percentage. }\end{array}$ & $\begin{array}{l}\text { Error estimations from - } \\
5.50 \% \text { to } 6.07 \% \text { from the } \\
\text { distance walked using two } \\
\text { camcoders. }\end{array}$ & $\begin{array}{l}16 \text { subjects } \\
\text { (Healthy, } \\
\text { Parkinson). }{ }^{20}\end{array}$ \\
\hline $\begin{array}{l}\text { Ziljstra } \\
\text { et al. }\end{array}$ & $\begin{array}{l}\text { Uni-axial } \\
\text { accelerometer }\end{array}$ & 1 & Waist & $\begin{array}{l}\text { Inverted } \\
\text { pendulum } \\
\text { model }\end{array}$ & $\begin{array}{l}\text { Double integration of the } \\
\text { accelerometer data using a } \\
\text { fourth order Butterworth filter } \\
\text { to attenuate the integration } \\
\text { error. }\end{array}$ & $\begin{array}{l}\text { General understimations } \\
\text { of } 16 \% \text { in the stride lenght } \\
\text { and the stride velocity } \\
\text { using a treadmill that } \\
\text { measures the ground } \\
\text { reactions forces. }\end{array}$ & $\begin{array}{l}15 \text { subjects } \\
\text { (Healthy, } \\
\text { Parkinson). }{ }^{29}\end{array}$ \\
\hline $\begin{array}{l}\text { Alvarez } \\
\text { et al. }\end{array}$ & $\begin{array}{l}\text { Uni-axial } \\
\text { accelerometer }\end{array}$ & 1 & Waist & $\begin{array}{l}\text { Inverted } \\
\text { pendulum } \\
\text { model }\end{array}$ & $\begin{array}{l}\text { Double integration of the } \\
\text { accelerometer data with the } \\
\text { zero-velocity detection } \\
\text { algorithm. }\end{array}$ & $\begin{array}{l}\text { Errors between } 1.4 \% \text { and } \\
4.4 \% \text { in } 170[\mathrm{~m}] \text { walked } \\
\text { using a camcoder. Only } \\
\text { presents results in long } \\
\text { distances. }\end{array}$ & $\begin{array}{l}8 \text { (Healthy) } \cdot^{30} \text { subjects } \\
\text { (H) }\end{array}$ \\
\hline $\begin{array}{l}\text { Salarian } \\
\text { et al. }\end{array}$ & $\begin{array}{l}\text { Uni-axial } \\
\text { gyroscope }\end{array}$ & 2 & $\begin{array}{l}\text { Left and } \\
\text { right shank }\end{array}$ & $\begin{array}{l}\text { Double } \\
\text { pendulum } \\
\text { model }\end{array}$ & $\begin{array}{l}\text { Shank angles using } \begin{array}{l}\text { Fourier } \\
\text { series and last square } \\
\text { optimization. }\end{array} \\
\end{array}$ & $\begin{array}{l}\text { Mean error of } \\
0.038 \pm 0.066[\mathrm{~m}] \text { using a } \\
\text { motion capture system. }\end{array}$ & $\begin{array}{l}\text { Three datasets of } \\
20 \text { (Training), } 36 \\
\text { (Testing) and } 15 \\
\text { (Evaluation) } \\
\text { subjects (Healthy, } \\
\text { Hip replacement, } \\
\text { Coxarthrosis). }{ }^{13}\end{array}$ \\
\hline $\begin{array}{l}\text { Doheny } \\
\text { et al. }\end{array}$ & IMU & 1 & $\begin{array}{l}\text { Left and } \\
\text { right shank }\end{array}$ & $\begin{array}{l}\text { Lower } \\
\text { body rigid } \\
\text { model }\end{array}$ & $\begin{array}{l}\text { Maximum angle between the } \\
\text { legs at its maximum extension } \\
\text { to obtain the stride length plus } \\
\text { an optimized corrective factor. }\end{array}$ & $\begin{array}{l}\text { Mean error of } 0.09 \pm 0.07 \\
{[\mathrm{~m}] \text { using the GAITRite }} \\
\text { pressure platform system. }\end{array}$ & $\begin{array}{l}7 \text { Subjects } \\
\text { (Healthy). }{ }^{21}\end{array}$ \\
\hline
\end{tabular}

\section{Mobile platform}

The measurement platform is a mobile application for Android, which ensures the portability, simplicity and comfort of the proposed system. The algorithm of González et al. ${ }^{23}$ was implemented in the mobile application with the method presented by Alvarez et al. ${ }^{30}$ through JavaScript using React Native. The mobile platform communicates with an application programming interface (API) to manage the database where the data is stored and communicate with the mobile application (see Figure 1b). The API was 


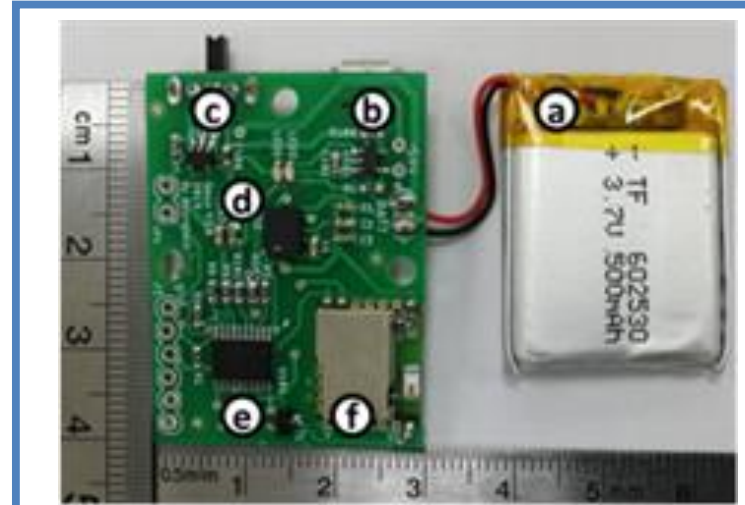

(a)

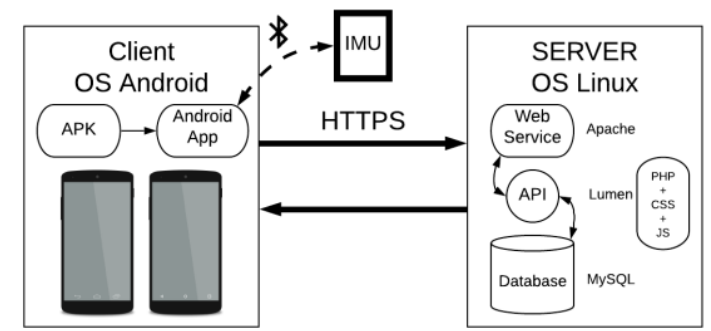

(b)

Fig 1. Top figure: IMU sensor implemented. a) Battery, b) Micro_USB battery charger unit, c) Power switch and voltage regulator, d) IMU integrated circuit, e) Microcontroller, f) Bluetooth. Bottom Figure: General scheme of the development and operation of the mobile platform.

implemented using the PHP framework Lumen Laravel version 5.8. The database contains all the information related to the user sessions, the list of subjects, the raw signals (accelerations, angular velocities and orientations) and the spatial-temporal parameters estimated by the application.

Table 2. Subject's characteristics for the spatialtemporal gait parameters estimation.

\begin{tabular}{llll}
\hline & $\begin{array}{l}\text { Mi } \\
\text { n }\end{array}$ & Max & Mean \\
\hline Age [Years] & 23 & 28 & $27.27 \pm 2$ \\
Height [m] & 1.51 & 1.94 & $1.70 \pm 0.1$ \\
Weight [kg] & 56 & 118 & $71.7 \pm 17.2$ \\
Right leg length [mm] & 825 & 960 & $889 \pm 49$ \\
$\begin{array}{l}\text { Left leg length [mm] } \\
\text { Right knee width }\end{array}$ & 825 & 950 & $889 \pm 47$ \\
[mm] & & & $94 \pm 7$ \\
$\begin{array}{l}\text { Left knee width [mm] } \\
\text { Right ankle width }\end{array}$ & 80 & 103 & $94 \pm 7$ \\
[mm] & & 78 & $70 \pm 4$ \\
$\begin{array}{l}\text { Left ankle width } \\
\text { [mm] }\end{array}$ & 65 & 78 & $71 \pm 5$ \\
\hline
\end{tabular}

\section{Test subjects}

Twenty healthy subjects (18 men and 2 women) were assessed (see Table 2) with the Vicon motion capture system (Oxford,. UK) model Bonita version 2.7.1 and the Polygon 4.4.2 analysis software. Subjects were asked to wear sport clothes and comfortable shoes to carry out the tests in order to avoid external factors that could modify their gait pattern. No subject was measured barefoot, since our intention was to assess the proposed system in the least ideal conditions within a laboratory for motion capture. Before the measurements were made, each subject signed an informed consent document. This was approved by the Scientific Ethical Committee of the Faculty of Medicine, University of Concepción (CEC102019). We also developed a set of criteria upon which prospective participants were to be screened before they could be confirmed to partake in the study. Exclusion criteria were: the diagnosis of a neurological, vestibular,

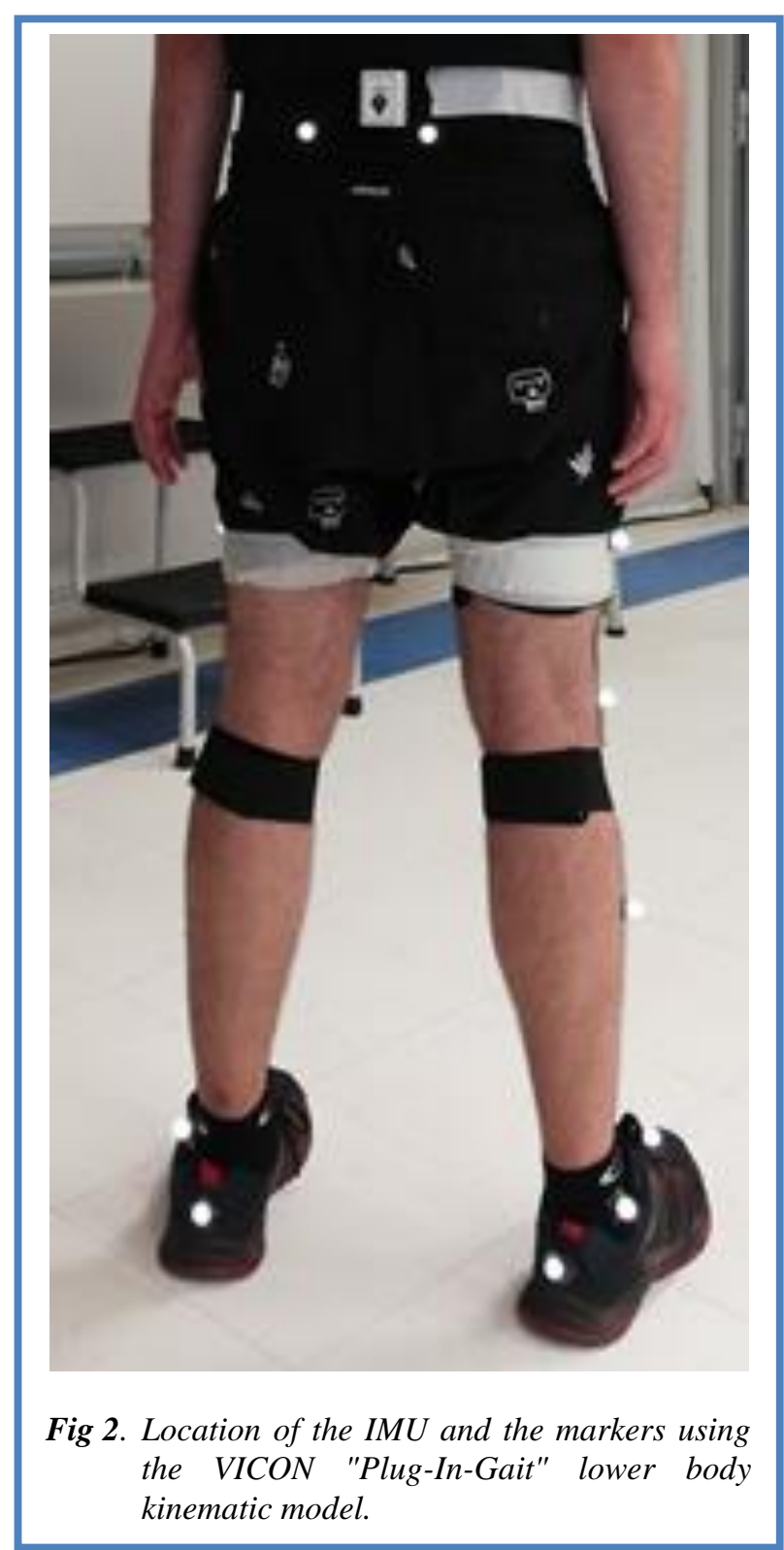


Table 3. Error estimations of the spatial temporal gait parameters.

\begin{tabular}{lccccccc}
\hline & $\begin{array}{c}\text { Cadence } \\
\text { [step/min } \\
\text { ] }\end{array}$ & $\begin{array}{c}\text { Stride time } \\
{[\mathrm{sec}]}\end{array}$ & $\begin{array}{c}\text { Step time } \\
{[\mathrm{sec}]}\end{array}$ & $\begin{array}{c}\text { Single support } \\
\text { time [sec] }\end{array}$ & $\begin{array}{c}\text { Double support } \\
\text { time [sec] }\end{array}$ & $\begin{array}{c}\text { Stance phase } \\
\text { duration [\%] }\end{array}$ & $\begin{array}{c}\text { Swing phase } \\
\text { duration [\%] }\end{array}$ \\
\hline Right leg error & $-2.35 \pm 5.02$ & $0.03 \pm 0.04$ & $0.02 \pm 0.03$ & \pm 0.02 & \pm 0.02 & $0.57 \pm 2.44$ & $-0.57 \pm 2.44$ \\
Left leg error & $0.21 \pm 6.36$ & $0.02 \pm 0.04$ & $0.01 \pm 0.04$ & \pm 0.02 & $0.01 \pm 0.02$ & $-0.15 \pm 2.25$ & $0.15 \pm 2.25$ \\
\hline
\end{tabular}

musculoskeletal or systemic disease that could alter the ability to walk; the diagnosis of any cardiovascular, respiratory or metabolic disease or other condition that could interfere with the present study; having undergone surgery on the trunk and lower limbs at least two years before the present study, the use of assistive devices for walking and the presence of serious visual alterations.

\section{Validation of spatial-temporal gait parameters estimations}

After the calibration of the motion capture system and the previous record of anthropometric and physical parameters of each subject (weight, height, legs length, knees width, ankles width), 16 reflective markers of 14 [mm] diameter were placed in the body of each subject according to the Vicon "Plug-In-Gait" lower body kinematic model, ${ }^{34}$ with the IMU sensor as indicated in Figure 2. Synchronization of the systems - Inertial and Optoelectronic - is not important, since the objective is not to revalidate the algorithms for the detection of the events of the gait cycle, but rather the estimation of the spatial-temporal parameters calculated by each system. For the measurements made in the opto-electronic movement laboratory, the spatial-temporal parameters were exported from Polygon 4.4.2 analysis software to a spreadsheet. These data were then compared with the measurements obtained by the mobile platform implemented for the detection of foot-off and heel strike events, and their processing for the estimation of cadence, stride time, step time, single support time, double support time, stride phase duration, swing phase duration and step length. Measurements were made from a rest state, that is, while subjects were standing without moving. In order to avoid singularities with respect to the actions of acceleration (beginning of gait), and deceleration (end of gait), the two initial seconds and the final two seconds were eliminated from each test. Spatial - temporal parameters such as walking speed or step velocity were not compared in this paper since they can be easily estimated from step length and step time obtained. So, to avoid redundancies, only the results of those parameters are presented.

\section{Performance analysis}

The performance analysis of the estimation of the spatial-temporal gait parameters, in which the optoelectronic motion capture system was used as gold--standard, comparisons on the distribution of the measurements, the estimation error of each of the parameters obtained and their respective correlation plots were made.

\section{Results}

\section{Temporal gait parameters}

To compare the results obtained from the spatialtemporal gait parameters estimated with the proposed technological system concerning those estimated with the motion capture system, distribution and error analysis of the measurements obtained for each subject were performed. The results on the distribution of the measurements are shown in Figure 3. The results of the average error obtained in the measurements are indicated in Table 3. From figure it can be seen that the distributions for each parameter are maintained within the measurements delivered by the motion capture system with differences in the extreme values as the parameters obtained by the motion capture system are from a single cycle. In contrast, for the proposed system, they have estimated as the average of the parameters of several gait cycles, it is clear that there are certain differences in the measurements. To compare the results obtained from the spatial-temporal gait parameters estimated with the proposed technological system concerning those estimated with the motion capture system, distribution and error analysis of the measurements obtained for each subject were performed. The results on the distribution of the measurements are shown in Figure 3. The results of the average error obtained in the measurements are indicated in Table 3. In the Figure 3 it can be seen that the distributions for each parameter are maintained within the measurements delivered by the motion capture system with differences in the extreme values, as the parameters obtained by the motion capture system are from a single cycle. In contrast, for the proposed system, they have estimated as the average of the parameters of several gait cycles, it is clear that there are certain differences in the measurements. As in this paper only young and healthy people where evaluated, it is expected that the values obtained for each limb will be similar using the same measurement system (see, for example, Figures $3 \mathrm{a}$ and $3 \mathrm{~b}$, or $3 \mathrm{e}$ and $\mathrm{f}$ ). Table 3 shows the average errors for each parameter measured. The best results obtained were the estimations of the single support time with an error of 0.02 [sec] for each leg and the double support time with an error of -0.02 [sec] for the right leg and $0.01 \pm 0.02$ [sec] for the left leg. The worst results obtained correspond to the cadence estimations, whit errors of $2.35 \pm 5.02[\mathrm{step} / \mathrm{min}]$ for the right $\mathrm{leg}$ and $0.21 \pm 6.36$ [step/min] for the left leg. 


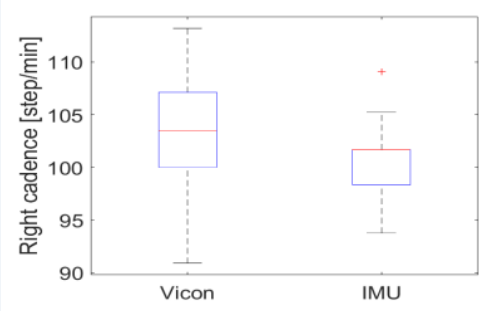

(a)

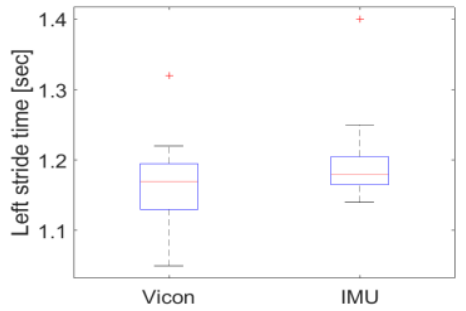

(d)

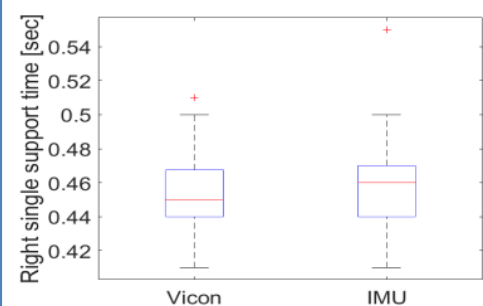

(g)

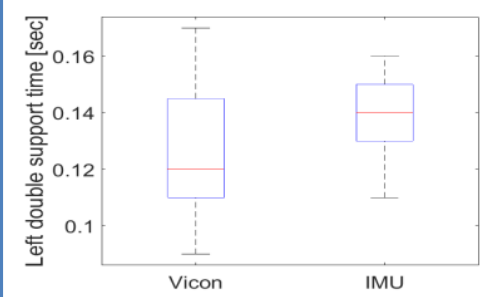

(j)

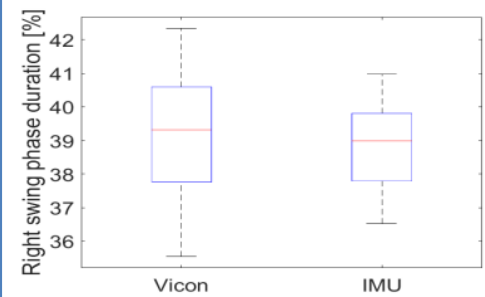

(m)

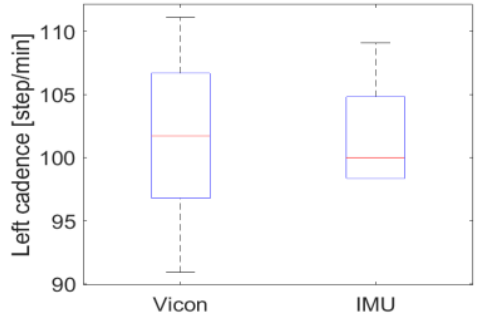

(b)

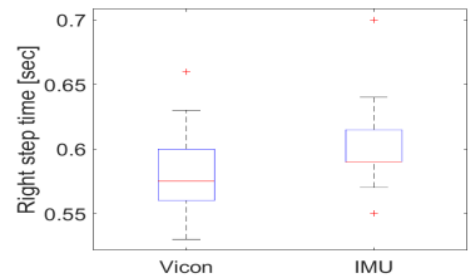

(e)

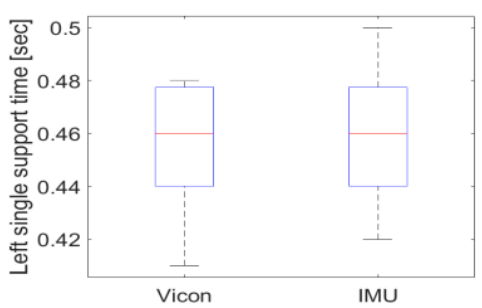

(h)

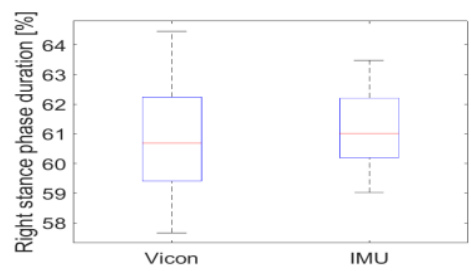

(k)

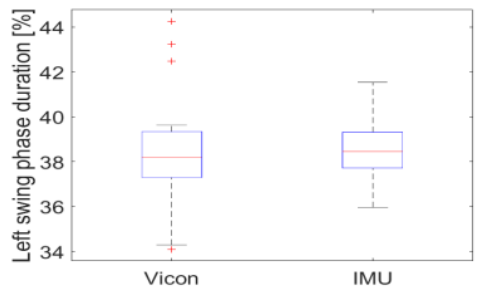

(n)

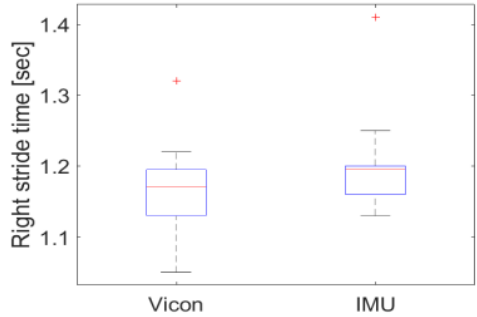

(c)

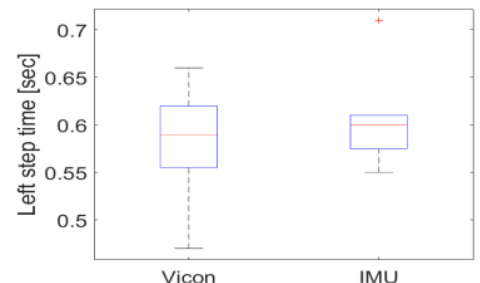

(f)

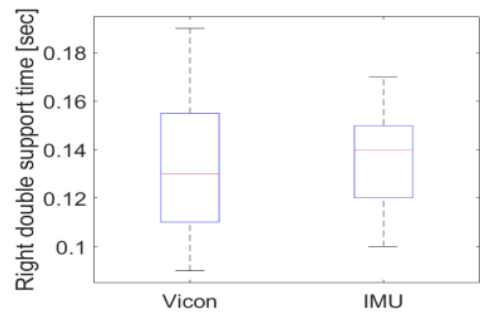

(i)

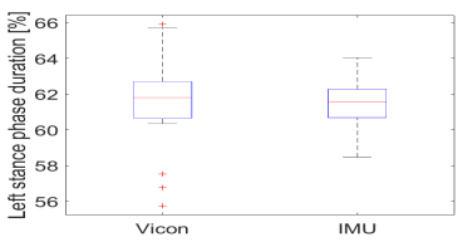

(l)

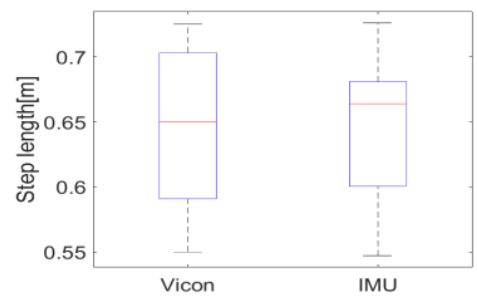

(o)

Fig 3. Results for the spatial temporal gait parameters estimations. Vicon: optoelectronic system measurements. IMU: developed system measurements.

\section{Step length}

Distribution analysis was used to compare the results of the estimation of the step length with that delivered by the motion capture system (see Figure 3). Only the data of one limb was used since the same measurements were obtained for both. The results for the distribution case are similar with respect to the measurements of the motion capture system (see Figure 3,o). About the average error of the estimations, a $0.01 \pm 0.03[\mathrm{~m}]$ was obtained for both legs. 


\section{Discussion}

A system based on a single IMU and a mobile analysis platform is proposed for an accurate, low-cost and friendly-use spatial-temporal gait parameters estimation. A review of methodologies using inertial sensors for the estimation of spatial-temporal gait parameters was presented. Although there are a large number of methodologies and algorithms for the detection of gait cycle events ${ }^{10,22,24-28}$ it was decided to use the same methodology of Gonzalez et al. ${ }^{23}$ for the simplicity of its implementation, the use of a single sensor and its location in the lower-back, which guarantees not only the estimation of the gait cycle parameters for both limbs but also the comfort of the subjects, constituting one of the few alternatives with these characteristics with validation using a GoldStandard system carried out with the Chilean population. In this paper, the validation for the detection of the IC and FC events was left aside, since these have been evaluated with good results in previous works ${ }^{23}$. For the estimation of the step length, the method presented by Alvarez et al. method was used because it presented good results in previous works even over long distances ${ }^{30}$. The selected algorithms were implemented on a mobile platform which ensures the portability and comfort of the measurement system. The results obtained show that it is possible to estimate the temporal gait parameters using our low-cost alternative with slight differences from the gold--standard (see Figure 3), reaching differences of \pm 0.02 [sec] for the double and single support time (see table 3), which correspond to the best results. The worst estimation corresponds to the gait cadence whit errors of $-2.35 \pm 5.02[\mathrm{step} / \mathrm{min}$ ] for the right leg and $0.21 \pm 6.36$ [step/min] for the left leg, due to the differences in the form of calculations of this parameter concerning the Vicon motion capture system. However, this does not represent a disadvantage for the proposed system considering that the measuring ranges are between 90 [step/min] and 110 [step/min] (see Figures 3a and 3b). All temporal parameters are within the ranges for healthy subjects, which is correct considering the sample. Over the step length, measurements similar to the Vicon motion capture system (see Figure 3o) were obtained with an error of $0.01 \pm 0.03[\mathrm{~m}]$ with a high concordance between the estimations, allowing to validate that the measurements, at least for healthy subjects, will not have a tremendous difference of $\pm 0.01[\mathrm{~m}]$ approximately. will not have a tremendous difference of \pm 0.01 [m] approximately. This research presents some limitations. It is not possible to determine how the proposed methodology would work in a pathological population or with neurological disorders, since it was only performed in young and healthy subjects, serving as a starting point to validate the proposed methodology. Clinical validation studies of these devices should be carried out in populations with specific characteristics related to gait and balance impairments. In conclusion, in this paper, we showed that a single IMU located on the back can be used to estimate spatial-temporal kinematic parameters with minimal differences from the VICON system in healthy Chilean subjects. The system proposed is user-friendly, low-cost and portable. It could be used by healthcare professionals with objective measurements to perform gait analysis in community or controlled environments.

\section{List of acronyms}

API - application programming interface

IMU - Inertial Measurement Units

$F C$ - or final contact

IC - or initial contact

PHP - Hypertext Preprocessor

\section{Authors contributions}

Conceptualization, PA, BG, CC and PO; Methodology, $P A, B G, C C, S C$, and PO; Software, BG, SC and CC; Data curation, $B G$ and $S C$; Formal analysis, $B G$ and $S C$; Resources, $P A, B G$ and FS; Writing-original draft, $P A$ and $B G$; Writing-review editing, $P A, B G, R C, C C, P O$ and FS; Supervision, $P A, R C$ and $C C$.

\section{Acknowledgments}

The authors would like to thank to the Preclinical and Clinical Sciences Department, Faculty of Medicine, Universidad Católica de la Santísima Concepción to support the investigation.

\section{Funding}

ANID Chile Ph.D. Scholarship program.

\section{Conflict of Interest}

The authors declare no competing interests.

\section{Ethical Publication Statement}

We confirm that we have read the Journal's position on issues involved in ethical publication and affirm that this report is consistent with those guidelines.

\section{Corresponding Author}

Britam Gómez, Electrical Engineering Department, Faculty of Engineering, Universidad de Concepción, Edmundo Larenas 219, Concepcion, 4030000, Biobio, Chile. ORCID iD: 0000-0001-6563-2955

E-mail: britam.gomez@biomedica.udec.cl

E-mail and ORCID iD of co-authors

Pablo Aqueveque: pablo.aqueveque@biomedica.udec.cl ORCID iD: 0000-0001-9101-0383

Francisco Saavedra: frsaaved@gmail.com ORCID iD: 0000-0002-7473-3763

Cristian Canales: E-mail: cristcanales@udec.cl ORCID iD: 0000-0002-7475-3350

Simón Contreras:simocontreras@udec.cl Paulina Ortega-Bastidas: portegab@udec.cl ORCID iD: 0000-0002-9333-3036

Roberto Cano-de-la-Cuerda: roberto.cano@urjc.es ORCID iD: 0000-0002-1118-4234 


\section{References}

1. Bright T, Wallace S, Kuper H. A systematic review of access to rehabilitation for people with disabilities in low-and middle-income countries. Int J Environ Res Public Health 2018;15:2165. doi: 10.3390/ijerph15102165

2. Flory SL. The prospects and challenges of bringing physical therapy to the physically disabled population in developing countries 2009.

3. Echeverry LLG, Henao AMJ, Molina MAR, et al. Human motion capture and analysis systems: a systematic review/Sistemas de captura y análisis de movimiento cinemático humano: una revisión sistemática. Prospectiva 2018,16,24-34.

4. Giannini S. Gait analysis: methodologies and clinical applications. Amsterdam: IOS Press for BTS Bioengineering Technology \& Systems 1994.

5. Watson MJ. Refining the Ten-metre Walking Test for Use with Neurologically Impaired People. Physiotherapy 2002;88:386-97.

6. Mayagoitia RE, Nene AV, Veltink PH. Accelerometer and rate gyroscope measurement of kinematics: an inexpensive alternative to optical motion analysis systems. J Biomech 2002;35:53742. doi: 10.1016/s0021-9290(01)00231-7.

7. Lau $\mathrm{H}$, Tong $\mathrm{K}$. The reliability of using accelerometer and gyroscope for gait event identification on persons with dropped foot. Gait Posture. 2008 Feb;27(2):248-57. doi: 10.1016/ j.gaitpost.2007.03.018

8. Yang C-C, Hsu Y-L. A Review of AccelerometryBased Wearable Motion Detectors for Physical Activity Monitoring. Sensors (Basel) 2010;10:7772-88. doi: 10.3390/s100807772

9. Buckley C, Galna B, Rochester L, Mazzà C. Quantification of upper body movements during gait in older adults and in those with Parkinson's disease: impact of acceleration realignment methodologies. Gait Posture. 2017;52:265-71. doi: 10.1016/j.gaitpost.2016.11.047

10. Jasiewicz JM, Allum JH, Middleton JW, et al. Gait event detection using linear accelerometers or angular velocity transducers in able-bodied and spinal-cord injured individuals. Gait Posture. 2006;24:502-9. doi: 10.1016/j.gaitpost.2005.12.017

11. Kim JW, Jang HJ, Hwang D-H, Park C. A Step, Stride and Heading Determination for the Pedestrian Navigation System. Journal of Global Positioning Systems. 2004;3(1\&2):273-9.

12. Sayeed T, Sama A, Catala A, Cabestany J. Comparison and adaptation of step length and gait speed estimators from single belt worn accelerometer positioned on lateral side of the body. 2013 IEEE 8th International Symposium on Intelligent Signal Processing. 2013;14-20.

13. Salarian A, Burkhard PR, Vingerhoets FJG, et al. A Novel Approach to Reducing Number of Sensing Units for Wearable Gait Analysis Systems. IEEE
Transactions on Biomedical Engineering 2013;60:72-7.

14. Glowinski S, Blazejewski A, Krzyzynski,T. Humangaitfeaturedetectionusinginertialsensorswav elets. In Wearable Robotics: Challenges and Trends; Springer, 2017; pp. 397-401.

15. Jee H. Review of researches on smartphone applications for physical activity promotion in healthy adults. Journal of Exercise Rehabilitation 2017;13:3-11.

16. Muro-De-La-Herran A, Garcia-Zapirain B, Mendez-Zorrilla A. Gait Analysis Methods: An Overview of Wearable and Non-Wearable Systems, Highlighting Clinical Applications. Sensors (Basel) 2014;14(2):3362-94. doi: 10.3390/s140203362

17. Paraschiv-Ionescu A, Newman CJ, Carcreff L, et al. Correction to: Locomotion and cadence detection using a single trunk-fixed accelerometer: validity for children with cerebral palsy in daily life-like conditions. J Neuroeng Rehabil 2019;16:27. doi: 10.1186/s12984-019-0498-8.

18. Carcreff L, Gerber C, Paraschiv-Ionescu A, et al. What is the Best Configuration of Wearable Sensors to Measure Spatiotemporal Gait Parameters in Children with Cerebral Palsy? Sensors (Basel) 2018;18(2):394. doi: 10.3390/s18020394

19. Trojaniello D, Cereatti A, Croce UD. Accuracy, sensitivity and robustness of five different methods for the estimation of gait temporal parameters using a single inertial sensor mounted on the lower trunk. Gait Posture. 2014;40(4):487-92. doi: 10.1016/j. gaitpost.2014.07.007

20. González RC, López AM, Rodriguez-Uría J, et al. Real-time gait event detection for normal subjects from lower trunk accelerations. Gait Posture. 2010;31(3):322-5. doi: 10.1016/j.gaitpost.2009. 11.014

21. Doheny EP, Foran TG, Greene BR. A single gyroscope method for spatial gait analysis. Conf Proc IEEE Eng Med Biol Soc 2010;2010:1300-3. doi: 10.1109/IEMBS.2010.5626397

22. Sejdic E, Lowry KA, Bellanca J, et al. Extraction of Stride Events From Gait Accelerometry During Treadmill Walking. IEEE J Transl Eng Health Med 2016;4:2100111. doi: 10.1109/JTEHM.2015.250 961

23. González RC, López AM, Rodriguez-Uría J, et al. Real-time gait event detection for normal subjects from lower trunk accelerations. Gait Posture 2010,31:322-5. doi: 10.1016/j.gaitpost.2009.11.014

24. Kose A, Cereatti A, Croce UD. Daily life activity classification using a single inertial measurement unit attached to the waist. Gait Posture 2012;35.

25. Mccamley J, Donati M, Grimpampi E, Mazzà C. An enhanced estimate of initial contact and final contact instants of time using lower trunk inertial sensor data. Gait Posture. 2012;36:316-8. 


\section{Portable system for spatial-temporal gait parameters}

Eur J Transl Myol 30 (2): 268-276, 2020

26. Aminian K, Rezakhanlou K, Andres ED, et al. Temporal feature estimation during walking using miniature accelerometers: an analysis of gait improvement after hip arthroplasty. Medical \& Biological Engineering \& Computing. 1999;37:686-91.

27. Sabatini A, Martelloni C, Scapellato S, Cavallo F. Assessment of Walking Features From Foot Inertial Sensing. IEEE Transactions on Biomedical Engineering. 2005;52:486-94.

28. Aminian K, Najafi B, Büla C, et al. Spatio-temporal parameters of gait measured by an ambulatory system using miniature gyroscopes. J Biomech 2002;35:689-99.

29. Zijlstra W, Hof AL. Assessment of spatio-temporal gait parameters from trunk accelerations during human walking. Gait Posture. 2003;18:1-10.

30. Alvarez JC, Alvarez D, López A, González RC. Pedestrian Navigation Based on a Waist-Worn Inertial Sensor. Sensors (Basel) 2012;12:10536-49.
31. Godfrey A, Del Din S, Barry G, et al. Instrumenting gait with an accelerometer: a system and algorithm examination. Medical engineering \& physics 2015;3: 400-47

32. BNO055 Intelligent 9-Axis Absolute Sensor [Internet]. Mouser Electronics - Electronic Components Distributor. 2019 [cited 2020 Feb 25]. Available from: https://www.mouser.com/new/ bosch/bosch-bno55-sensor/

33. Ang M, Tourassis V. Singularities of Euler and Roll-Pitch-Yaw Representations. IEEE Transactions on Aerospace and Electronic Systems. 1987;AES-23(3):317-24.

34. Davis RB, Õunpuu S, Tyburski D, Gage JR. A gait analysis data collection and reduction technique. Human Movement Science 1991;10:575-87.

Submission: April 1, 2020

Revision received: May 22, 2020

Accepted for publication: May 23, 2020 